\title{
Spreadsheets to expedite taxonomic publications by automatic generation of morphological descriptions and specimen lists
}

\section{Visual guide, v1.2}

\author{
by Ivan L.F. Magalhaes
}

División Aracnología, Museo Argentino de Ciencias Naturales "Bernardino Rivadavia" - CONICET .

Av. Ángel Gallardo 470, C1405DJR, Buenos Aires, Argentina. E-mail: magalhaes@macn.gov.ar

$* * *$

This manual explains the use of a group of three spreadsheets that are intended to help the writing of taxonomic works by automatically generating textual outputs for sections whose writing is generally tedious and time-consuming: the description of specimens, summaries of measurement variation and lists of examined material. Each of the spreadsheets is explained in detail in the following pages. Spreadsheets are protected to avoid that users accidentally modify formulas or other important content, but they can be unlocked and edited without the need for a password.

If using these spreadsheets, please cite: Magalhaes, ILF (2019) Spreadsheets to expedite taxonomic publications by automatic generation of morphological descriptions and specimen lists. Zootaxa. 


\section{Descriptions}

This spreadsheet outputs specimen descriptions. Each row corresponds to an individual description (e.g. the male of Filistatinella hermosa). Column A identifies the species. Columns C-F refer to sex/stage, type status, locality and collection number and all are printed in the beginning of the description. In the example below, the output from row 5 is "Male holotype from 32 miles E Laredo, Texas, USA (AMNH, IFM-1219)."

\begin{tabular}{|c|c|c|c|c|c|c|c|}
\hline 4 & A & $B$ & C & $\mathrm{D}$ & $\mathrm{E}$ & $\mathrm{F}$ & G \\
\hline 1 & & & & & Tags for description headers & sheader: & \multirow{4}{*}{ Coloration } \\
\hline 2 & & & & & Tags for master characters & єє€€ & \\
\hline 3 & & & & & Number of decimal digits for measurements: & 2 & \\
\hline 4 & Species & Obs' & Sex/stage & Type specimen & From & Voucher & \\
\hline 5 & Filistatinella crassipalpis & & Male & holotype & 32 miles E Laredo, Texas, USA & AMNH, IFM-1219 & \\
\hline 6 & Filistatinella crassipalpis & & Female & & 32 miles E Laredo, Texas, USA & AMNH, IFM-1220 & as in male \\
\hline
\end{tabular}

Columns G onwards contain characters. The first row contains character headers, which can be used to separate your description into body regions; these headers are printed to the output. The second row contains master characters, which initiate new sentences in descriptions, and thus their name is also printed to the output. In the example below, the description of row 4 would read "Cephalothorax. Anterior margin of the carapace unmodified. Total 1ength 1.66." Please note that characters are only printed to the text of a particular species if the corresponding cell has data. In the example below, the description of row 4 would not mention its "Sternum", since the corresponding cells lack data. Important: if there are multiple columns referring to the same header and master character, and at least one of them contains data, data should be inputted in the first column mentioning the header or master character, otherwise they will not be printed to the output. Also, columns referring to the same header or master character should be consecutive, otherwise they will be printed multiple times.

\begin{tabular}{|c|c|cccc|}
\hline 4 & A & U & V & W & $X$ \\
\hline 1 & & Cephalothorax & & \\
2 & & Anterior margin of the carapace & Sternum & Sternum & Total length \\
3 & & & & \\
& & shape & sigillae & \\
\hline 4 & Species & & & & 1.66 \\
\hline 5 & Filistatinella crassipalpis & unmodified & & 1.6 \\
\hline 6 & Filistatinella crassipalpis & unmodified & & & \\
\hline
\end{tabular}




\begin{tabular}{|c|c|c|c|c|c|c|c|c|c|c|c|c|}
\hline 4 & A & B & c & D & $\mathrm{E}$ & $\mathrm{F}$ & $\mathrm{u}$ & v & W & $\mathrm{x}$ & $\mathrm{Y}$ & z \\
\hline 1 & & & & & Tags for description headers & sheader: & \multirow{4}{*}{$\begin{array}{l}\text { Cephalothorax } \\
\text { Anterior margin of the carapace }\end{array}$} & \multirow{3}{*}{ Sternum } & \multirow{3}{*}{ Sternum } & \multirow{4}{*}{ Total length } & \multirow{4}{*}{$\begin{array}{l}\text { Carapace } \\
\text { length }\end{array}$} & \multirow{4}{*}{$\begin{array}{c}\text { Carapace } \\
\text { width }\end{array}$} \\
\hline 2 & & & & & Tags for master characters & €€€ & & & & & & \\
\hline 3 & & & & & Number of decimal digits for measurements: & 2 & & & & & & \\
\hline 4 & Species & Obs & Sex/stage & Type specimen & From & Voucher & & shape & sigillae & & & \\
\hline 5 & Filistatinella crassipalpis & & Male & holotype & 32 miles E Laredo, Texas, USA & AMNH, IFM-12 & unmodified & rounded & sigillae not visible & 1.66 & 0.75 & 0.7 \\
\hline 6 & Filistatinella crassipalpis & & Female & & 32 miles E Laredo, Texas, USA & AMNH, IFM-12 & unmodified & rounded & sigillae not visible & 1.6 & 0.7 & 0.62 \\
\hline 7 & Filistatinella pistrix & & Male & & San Bern. National Forest, Riverside, California, USA & AMNH, IFM-11 & unmodified & rounded & sigillae not visible & 2.33 & 0.99 & 0.93 \\
\hline 8 & Filistatinella pistrix & & Female & & San Bern. National Forest, Riverside, California, USA & AMNH, IFM-11 & unmodified & rounded & sigillae not visible & 2.60 & 1.04 & 0.90 \\
\hline 9 & Filistatinella hermosa & & Male & & Altadena, California, USA & MCZ 65568 & unmodified & rounded & sigillae not visible & 2.03 & 0.86 & 0.82 \\
\hline 10 & Filistatinella hermosa & & Female & & Santa Cruz Island, California, USA & AMNH, prep. IFM & unmodified & rounded & sigillae not visible & 2.23 & 0.84 & 0.84 \\
\hline
\end{tabular}

If several descriptors refer to the same master character, its name is printed only once at the beginning of the sentence.

Character headers (row 1) and master characters (row 2) can be tagged so they can be easily formatted latter. To tag them, introduce the corresponding tags into cells F1 and F2, respectively. Tagging is optional and these fields can be left blank. You can also use tags that describe format intuitively (e.g., <bold>, <ital>, <smallcaps >, etc).

If tagging is enabled, the output for row 5 in the example above would read "<header>cephalothorax<header>. $€ € €$ Anterior margin of the carapace $€ €$ unmodified. $€ € € S t e r n u m € € €$ rounded, sigillae not visible. $€ € €$ Total length€€€ 1.66.".

By applying the instructions explained below (see Formatting the text using tags below), one can use these tags to easily apply custom formatting to all descriptions in the manuscript. An example of formatted description would be applying bold + small caps to headers and italics to master characters:

Cephalothorax. Anterior margin of the carapace unmodified. Sternum rounded, sigillae not visible. Total length 1.66. 
The third row contains subordinate characters. These are also printed to the text, but only continue sentences already started by master characters. In the example below, the description of row 5 would read "Leg I: femur (fe) 0.88 , pate11a (pa) 0.28 , tibia (ti) 0.84 , metatarsus (mt) 0.78 , tarsus (ta) 0.46 . II: fe 0.75 , pa 0.26, ti $0.67, \mathrm{mt} 0.65$, ta $0.33 "$.

\begin{tabular}{|c|c|c|c|c|c|c|c|c|c|c|c|}
\hline 4 & $A$ & $\mathrm{AO}$ & $\mathrm{AP}$ & $\mathrm{AQ}$ & AR & AS & AT & $\mathrm{AU}$ & AV & AW & $A X$ \\
\hline 1 & & \multirow{4}{*}{$\begin{array}{c}\text { Leg I: } \\
\text { femur (fe) }\end{array}$} & \multirow{4}{*}{$\begin{array}{c}\text { Leg I: } \\
\text { patella (pa) }\end{array}$} & \multirow{4}{*}{$\begin{array}{l}\text { Leg I: } \\
\text { tibia (ti) }\end{array}$} & \multirow{4}{*}{$\begin{array}{c}\text { Leg l: } \\
\text { metatarsus (mt) }\end{array}$} & \multirow{4}{*}{$\begin{array}{c}\text { Leg l: } \\
\text { tarsus (ta) }\end{array}$} & \multirow{4}{*}{$\begin{array}{l}\text { Il: } \\
\text { fe }\end{array}$} & \multirow{4}{*}{$\begin{array}{l}\text { II: } \\
\text { pa }\end{array}$} & \multirow{4}{*}{$\begin{array}{l}\text { II: } \\
\text { ti }\end{array}$} & \multirow{4}{*}{$\begin{array}{l}\text { II: } \\
\text { mt }\end{array}$} & \multirow{4}{*}{$\begin{array}{l}\text { Il: } \\
\text { ta }\end{array}$} \\
\hline 2 & & & & & & & & & & & \\
\hline 3 & & & & & & & & & & & \\
\hline 4 & Species & & & & & & & & & & \\
\hline 5 & Filistatinella crassipalpis & 0.88 & 0.28 & 0.84 & 0.78 & 0.46 & 0.75 & 0.26 & 0.67 & 0.65 & 0.33 \\
\hline 6 & Filistatinella crassipalpis & 0.74 & 0.25 & 0.65 & 0.55 & 0.41 & 0.6 & 0.22 & 0.5 & 0.47 & 0.33 \\
\hline 7 & Filistatinella pistrix & 1.14 & 0.32 & 1.03 & 1.03 & 0.58 & 1.01 & 0.33 & 0.93 & 0.98 & 0.46 \\
\hline 8 & Filistatinella pistrix & 0.97 & 0.32 & 0.88 & 0.82 & 0.52 & 0.85 & 0.33 & 0.74 & 0.75 & 0.43 \\
\hline 9 & Filistatinella hermosa & 0.97 & 0.32 & 0.88 & 0.85 & 0.46 & 0.86 & 0.28 & 0.77 & 0.75 & 0.36 \\
\hline 10 & Filistatinella hermosa & 0.86 & 0.32 & 0.77 & 0.71 & 0.46 & 0.72 & 0.26 & 0.61 & 0.6 & 0.38 \\
\hline
\end{tabular}

The fourth row is not printed to the text; use it for comments, reminders, etc. The column headers are fully customizable, so change the character names to fit your purposes. All the characters are output in the order the columns are arranged. The current version of the spreadsheet supports 99 unique descriptors. If anyone should need to prepare descriptions with a larger number of characters, please let me know. Important: if you wish to add, remove, or rearrange the order of the characters, do not cut (ctrl+X) and paste data, and do not insert or delete columns. Use copy (ctrl+c) and paste to move data between columns G-DA and accommodate the characters. Cutting, inserting or deleting columns do not affect the formulas that concatenate the text, so if you make changes using these functions the reordering will not affect the output.

As you input the data, the descriptions are outputted in the final description sheet. Just copy the contents of the cells in column B (see below) and paste them into your favourite word processor.

\begin{tabular}{|c|c|c|c|c|c|c|c|c|c|c|c|c|}
\hline 2 & A & B & C & $\mathrm{D}$ & $\mathrm{E}$ & $\mathrm{F}$ & G & $\mathrm{H}$ & T & $\mathrm{J}$ & K & L \\
\hline 1 & Species & Description & & & & & & & & & & \\
\hline 2 & Filistatinella crassipalpis & \multicolumn{11}{|c|}{ Male holotype from 32 miles E Laredo, Texas, USA (AMNH, IFM-1219). Carapace light brown, with very faint median pattern and submarginal bands, border lined with brown. Che } \\
\hline 3 & Filistatinella crassipalpis & \multicolumn{11}{|c|}{ Female from 32 miles E Laredo, Texas, USA (AMNH, IFM-1220). Coloration as in male. Anterior margin of the carapace unmodified. Sternum rounded, sigillae not visible. Total leng } \\
\hline 4 & Filistatinella pistrix & \multicolumn{11}{|c|}{ Male from San Bern. National Forest, Riverside, California, USA (AMNH, IFM-1167). Carapace brown, covered with white setae, with blackish median pattern, and faint submargin } \\
\hline 5 & Filistatinella pistrix & \multicolumn{11}{|c|}{ Female from San Bern. National Forest, Riverside, California, USA (AMNH, IFM-1192). Coloration as in male. Anterior margin of the carapace unmodified. Sternum rounded, sigillae } \\
\hline 6 & Filistatinella hermosa & \multicolumn{11}{|c|}{ Male from Altadena, California, USA (MCZ 65568). Carapace yellowish brown, with faint median pattern and submarginal bands, border lined with brown. Chelicerae yellowish b } \\
\hline 7 & Filistatinella hermosa & \multicolumn{11}{|c|}{ Female from Santa Cruz Island, California, USA (AMNH, prep. IFM-1232). Coloration as in male, but much generally much darker; carapace dark brown; rings on legs much more } \\
\hline
\end{tabular}




\section{Variation}

This spreadsheet summarizes meristic counts and measurements. Each row should contain data for a single specimen. For the algorithm to work, the data should be sorted by species (column B) and then by sex/stage (column C). Row 3 contains character headers, which are included in the final output. The formula counts the number of measured individuals and fetches the minimum and maximum values of each character; outputting averages and standard deviations is optional (switch them on/off by typing "y" or " $\mathrm{n}$ " in the corresponding cells, A2 and C2). If a particular character is inputted in the table but you do not want it to be outputted to the final text (e.g. because you only needed it to calculate a ratio), you can prevent it from being outputted by typing " $\mathrm{n}$ " in the corresponding cell in row 2 (see example below: an " $n$ " in J2 prevents "femur I length" from being outputted). Missing values are accepted, but the corresponding cell should have a textual string (such as a dash, -), otherwise it is interpreted as a zero.

\begin{tabular}{|c|c|c|c|c|c|c|c|c|c|}
\hline 4 & A & B & $\mathrm{C}$ & D & $\mathrm{H}$ & I & J & K & L \\
\hline 1 & print mean values $(\mathrm{Y} / \mathrm{N})$ ? & number of decimal values & print $\mathrm{SD}(\mathrm{Y} / \mathrm{N})$ ? & number of decimal values & Print? & & & & \\
\hline 2 & $y$ & 2 & $n$ & 2 & & & $n$ & & \\
\hline 3 & & species & sex/stage & voucher_identifier & total length' & carapace length & femur I length & tibia I length & femur/carapace ratio \\
\hline 4 & & Filistatinella howdyall & Males & & 2.3 & 0.75 & 0.99 & 0.98 & 1.32 \\
\hline 5 & & Filistatinella howdyall & Males & & 1.9 & 0.76 & 0.97 & 0.89 & 1.28 \\
\hline 6 & & Filistatinella howdyall & Males & & - & 0.95 & 1.3 & - & 1.37 \\
\hline 7 & & Filistatinella howdyall & Males & & 2.5 & 0.85 & - & - & - \\
\hline 8 & & Filistatinella howdyall & Males & & 2.2 & 0.96 & - & - & - \\
\hline 9 & & Filistatinella howdyall & Females & & 2.2 & 0.93 & 1.1 & 1 & 1.18 \\
\hline 10 & & Filistatinella howdyall & Females & & 2.6 & 1 & 1.2 & 1.1 & 1.2 \\
\hline 11 & & Filistatinella howdyall & Females & & 2.6 & 0.77 & 0.88 & 0.81 & 1.14 \\
\hline 12 & & Filistatinella howdyall & Females & & 2.6 & 1 & 0.98 & - & 0.98 \\
\hline 13 & & Filistatinella howdyall & Females & & 2.6 & 1.1 & 1.2 & - & 1.09 \\
\hline 14 & & Filistatinella domestica & Males & & 2.4 & 1 & 1.3 & 1.3 & 1.3 \\
\hline 15 & & Filistatinella domestica & Males & & 2.34 & 0.91 & 1.09 & 1.13 & 1.2 \\
\hline 16 & & Filistatinella domestica & Males & & 2.77 & 1.15 & 1.54 & 1.5 & 1.34 \\
\hline
\end{tabular}

The final text is outputted to the sheet variation per species; results are given separately by each sex/stage. Just copy the contents of the cells in column C (see below) and paste them into your favourite word processor.

\begin{tabular}{|c|c|c|}
\hline 2 & B & $\mathrm{C}$ \\
\hline 1 & Species & Variation \\
\hline 2 & Filistatinella howdyall & Males $(n=5)$ : total length $1.90-2.50(2.23)$, carapace length $0.75-0.96(0.85)$, tibia I length $0.89-0.98(0.94)$, femur/carapace ratio $1.28-1.37(1.32)$. \\
\hline 3 & Filistatinella howdyall & Females $(n=5)$ : total length $2.20-2.60(2.52)$, carapace length $0.77-1.10(0.96)$, tibia I length $0.81-1.10(0.97)$, femur/carapace ratio $0.98-1.20(1.12)$. \\
\hline 4 & Filistatinella domestica & Males $(n=4)$ : total length $2.34-2.77(2.5)$, carapace length $0.91-1.15(1.05)$, tibia I length $1.13-1.50$ (1.32), femur/carapace ratio $1.20-1.34$ (1.26). \\
\hline
\end{tabular}




\section{Material examined}

This spreadsheet generates lists of examined specimens sorted by locality. Data can be inputted in the following fields: Collection number, Species, Type status, stage1, stage2, stage3, stage4, stage5, Country, Admin1, Admin2, Locality1, Locality2, Habitat, Collecting method, Altitude, Coordinates, Collector, Date, Obs. Inputting data is only mandatory for the Species and Country fields (if there is no country data, I suggest inputting "No locality data" in this field); inputting data into Collection number and Admin1 fields is also strongly recommended. Other fields can be left blank and this will not affect the output. The headers of columns referring to stages $(F-J)$ are printed to the text, so the user should rename them according to their needs (male, \#f, + , immature, worker, etc.); these columns should contain the number of individuals.

\begin{tabular}{|c|c|c|c|c|c|c|c|c|c|c|c|c|c|}
\hline 4 & $\mathrm{C}$ & $D$ & $\bar{E}$ & $F$ & $\bar{G}$ & $\mathrm{H}$ & I & J & $\bar{K}$ & & $\bar{L}$ & $\mathrm{M}$ & $\mathrm{N}$ \\
\hline 1 & tag for country & tag for admin1 & tag for admin2 & & & & & & & & & & \\
\hline 2 & \#\# & sss & $\% \% \%$ & & & & & & & & & & \\
\hline 3 & tag for type headers $\gg$ & \&\&\& & & & e name & & & & & & & & \\
\hline 4 & Collection number $\nabla$ & Species & Type status $\nabla$ & $\# \mathrm{~m} \vee$ & $\# f f$ & imm. $\nabla$ & $\# x \sim$ & $\# y-$ & Country & $\nabla$ & Admin $1 \quad \nabla$ & Admin2 & Locality1 \\
\hline 5 & CAS 9057843 & Filistatinella domestica & & 3 & 0 & 0 & & & Mexico & & Chiapas & Lagunas de Montebello & Posada de Bosque Bellc \\
\hline 6 & AMNH IFM-1209 & Filistatinella domestica & & 0 & 1 & 0 & & & Mexico & & Estado de México & Almoloya de Juárez & Mina México \\
\hline 7 & AMNH IFM-1208 & Filistatinella domestica & & 1 & 0 & 0 & & & Mexico & & Estado de México & Almoloya de Juárez & Mina México \\
\hline 8 & AMNH & Filistatinella domestica & & 0 & 2 & 0 & & & Mexico & & Hidalgo & 2 miles NE Tizayuca & \\
\hline 9 & AMNH & Filistatinella domestica & & 0 & 3 & 3 & & & Mexico & & Hidalgo & 5 miles NW Actopan & \\
\hline 10 & AMNH & Filistatinella domestica & & 0 & 2 & 2 & & & Mexico & & Hidalgo & 5 miles S Zimapan & \\
\hline 11 & AM KS. 32582 & Filistatinella domestica & & 1 & 1 & 0 & & & Mexico & & Hidalgo & |xmiquilpan & Río Tula \\
\hline 12 & AMNH & Filistatinella domestica & & 0 & 2 & 0 & & & Mexico & & Hidalgo & bxmiquilpan & Rio Tula \\
\hline 13 & AMNH IFM-1211 & Filistatinella domestica & & 11 & 10 & 0 & & & Mexico & & Hidalgo & xmiquilpan & Río Tula \\
\hline 14 & AMNH IFM-1158 & Filistatinella domestica & & 1 & 1 & 0 & & & Mexico & & Hidalgo & Taxquillo (Tzindejeh) & \\
\hline 15 & AMNH IFM-1163 & Filistatinella domestica & & 0 & 1 & 0 & & & Mexico & & Oaxaca & 9 miles SE Nochixtlan & \\
\hline 16 & AMNH & Filistatinella domestica & & 0 & 1 & 0 & & & Mexico & & Puebla & Ozumbilla & \\
\hline 17 & AMNH & Filistatinella domestica & & 0 & 1 & 0 & & & Mexico & & San Luis de Potosí & 4 miles W San Luis de Potos & osí \\
\hline
\end{tabular}


Before inputting the data, the concat sheet can be used to concatenate geographical coordinates and collecting dates into single columns. The data separator can be defined by the user. To concatenate the coordinates, the user should also include the brackets. While this adds an extra step, different records can have different brackets; I use this to differentiate between records whose original label included coordinates from those which I georeferenced myself. Including the altitude at this step is optional, as there is a separate column for it in the data sheet. Important: when copying data from the concat to the data sheets, remember to paste values (Ctrl + Alt $+V$, check the 'values' box, or right click $>$ Paste special $>$ values).

\begin{tabular}{|c|c|c|c|c|c|c|c|c|c|}
\hline M & $\mathrm{N}$ & $\mathrm{O}$ & $P$ & Q & $\mathrm{R}$ & S & $\mathrm{T}$ & $\mathrm{U}$ & V \\
\hline \multicolumn{5}{|c|}{ Concatanate coordinates in the decimal forma } & \multirow[b]{3}{*}{ concat! } & \multicolumn{4}{|c|}{ Concatenate dates } \\
\hline & & \multicolumn{2}{|c|}{ Altitude given in...: } & $\mathrm{m}$ & & \multicolumn{2}{|c|}{ Separator: } & \multirow{2}{*}{\begin{tabular}{|c|}
1 \\
year
\end{tabular}} & \multirow[b]{2}{*}{ concat! } \\
\hline bracket1 & Lat-decimal & Long-decimal & Alt & bracket2 & & day & month & & \\
\hline[ & 22.319191 & -102.167831 & & ] & {$\left[\mathrm{N} 22.31919^{\circ}, \mathrm{W} 102.16783^{\circ}\right]$} & 30 & VIII & 1965 & $30 / \mathrm{VIII} / 1965$ \\
\hline [ & 21.695222 & -101.77337 & & ] & {$\left[\mathrm{N} 21.69522^{\circ}, \mathrm{W} 101.77337^{\circ}\right]$} & 29 & XII & 1943 & 29/XII/1943 \\
\hline( & 19.49 & -103.05 & & ) & $\left(\mathrm{N} 19.49^{\circ}, \mathrm{W} 103.05^{\circ}\right)$ & 10 & v & 1963 & $10 / V / 1963$ \\
\hline ( & 20.59 & -104.02 & & ) & $\left(\mathrm{N} 20.59^{\circ}, \mathrm{W} 104.02^{\circ}\right)$ & 13 & v & 1963 & $13 / V / 1963$ \\
\hline( & 19.57 & -102.42 & & ) & $\left(\mathrm{N} 19.57^{\circ}, \mathrm{W} 102.42^{\circ}\right)$ & 11 & v & 1963 & $11 / V / 1963$ \\
\hline( & 19.59 & -102.41 & & ) & $\left(\mathrm{N} 19.59^{\circ}, \mathrm{W} 102.41^{\circ}\right)$ & 9 & v & 1963 & 9/N/1963 \\
\hline( & 19.70180556 & -101.1995278 & & ) & $\left(\mathrm{N} 19.70181^{\circ}, \mathrm{W} 101.19953^{\circ}\right)$ & $20-25$ & VII & 2014 & $20-25 / \mathrm{VII} / 2014$ \\
\hline( & 19.70180556 & -101.1995278 & & ) & $\left(\mathrm{N} 19.70181^{\circ}, \mathrm{W} 101.19953^{\circ}\right)$ & $20-25$ & VII & 2014 & $20-25 / \mathrm{VII} / 2014$ \\
\hline ( & 19.70225 & -101.1989444 & 1915 & ) & $\left(\mathrm{N} 19.70225^{\circ}, \mathrm{W} 101.19894^{\circ}, 1915 \mathrm{~m}\right)$ & 23 & VII & 2014 & $23 / \mathrm{VII} / 2014$ \\
\hline [ & 19.70180556 & -101.1995278 & & ] & {$\left[\mathrm{N} 19.70181^{\circ}, \mathrm{W} 101.19953^{\circ}\right]$} & $20-25$ & VII & 2014 & $20-25 / \mathrm{VII} / 2014$ \\
\hline( & 19.70180556 & -101.1995278 & & ) & $\left(\mathrm{N} 19.70181^{\circ}, \mathrm{W} 101.19953^{\circ}\right)$ & $20-25$ & VII & 2014 & $20-25 / \mathrm{VII} / 2014$ \\
\hline( & 19.70180556 & -101.1995278 & & ) & $\left(\mathrm{N} 19.70181^{\circ}, \mathrm{W} 101.19953^{\circ}\right)$ & $20-25$ & VII & 2014 & $20-25 / \mathrm{VII} / 2014$ \\
\hline
\end{tabular}

The convert sheet can convert coordinates from degree-minutes-seconds to decimals and vice-versa. If you input degreesminutes-seconds, please indicate the hemisphere using letters ( $\mathrm{N}$ for north, $\mathrm{S}$ for south, $\mathrm{E}$ for east and W for west). When inputting coordinates as decimals, indicate the hemisphere by using positive (north, east) or negative (south, west) values. Failing to do so will result in the conversion returning an incorrect value. 
Optionally, users can define the type status of the specimens. To do that, fill the following codes in the Type status (column $\mathrm{E}): \mathrm{ht}=$ holotype, $\mathrm{pt}=$ paratype, $\mathrm{It}=$ lectotype, $\mathrm{nt}=$ neotype, $\mathrm{pl}=$ paralectotype, $\mathrm{st}=$ syntype. Each category of type will have a separate list of examined material.

After all specimen and locality data has been inputted in the data sheet, it must be sorted in either of these two orders:

1) Species, Type status, Country, Admin1, Admin2, Locality1, Locality2, Habitat, Method, Coordinates, Collector, Date

2) Species, Type status, Order-Country, Order-Admin1, Admin2, Locality1, Locality2, Habitat, Method, Coordinates, Collector, Date

If you choose option 1, localities will be listed in alphabetical order. If you choose option 2, you can manually define the order in which countries and first-level administrative units are listed. To manually define this order, go to the order-admin-units sheet and enable manual ordering by entering " $\mathrm{y}$ " in cell I1. A list of your localities should appear in columns $\mathrm{H}$ and $\mathrm{J}$ (you might need to refresh formulas by hitting F9, and this might take a while). After they appear, define the order they should be listed in by inputting numbers in the columns I and $\mathrm{K}$ and sort your data using option 2 (see above).

\begin{tabular}{|c|c|c|c|c|}
\hline 4 & $\mathrm{H}$ & I & J & $\mathrm{K}$ \\
\hline 1 & Order manually? $(y / n)$ & $\mathrm{y}$ & & \\
\hline 2 & Country & User defined order & Admin 1 & User defined order \\
\hline 3 & Mexico & 2 & Mexico@Aguas Calientes & 3 \\
\hline 4 & United States of America & 1 & Mexico@Chiapas & 12 \\
\hline 5 & & & Mexico@Estado de México & 8 \\
\hline 6 & & & Mexico@Hidalgo & 7 \\
\hline 7 & & & Mexico@Jalisco & 4 \\
\hline 8 & & & Mexico@Michoacán & 5 \\
\hline 9 & & & Mexico@Nayarit & 1 \\
\hline 10 & & & Mexico@Oaxaca & 11 \\
\hline 11 & & & Mexico@Puebla & 10 \\
\hline 12 & & & Mexico@San Luis de Potosí & 6 \\
\hline 13 & & & Mexico@Tamaulipas & 9 \\
\hline 14 & & & Mexico@Zacatecas & 2 \\
\hline 15 & & & United States of America@Arizona & 2 \\
\hline 16 & & & United States of America@California & 1 \\
\hline 17 & & & United States of America@New Mexico & 3 \\
\hline 18 & & & United States of America@Texas & 4 \\
\hline
\end{tabular}


Locality names and type headers can be tagged using user-defined strings, such as $\$ \$ \$$, \#\#, <country $>,<$ bold $>,<i>$ etc. This allows the user to easily apply formatting to the list afterwards (see Formatting the text using tags below). Tagging is optional, so these fields can be left blank. You may also define na abbreviation to be printed after collector's names (e.g. coll., leg.).

\begin{tabular}{|c|c|c|c|}
\hline 4 & C & D & E \\
\hline 1 & tag for country & tag for admin1 & tag for admin2 \\
2 & $\# \#$ & SSs & $\% \%$ \\
\hline 3 & tag for type headers $\gg$ & \&\&\& & \\
\hline 4 & Collection number $>$ & Species & Type status \\
\hline
\end{tabular}

Important: remember to sort your data, otherwise the lists will be printed incorrectly! The lists are outputted to the Ready! sheet and given by species. Just copy the contents of the cells in column C (see below) and paste them into your favourite word processor.

\begin{tabular}{|c|c|c|}
\hline 4 & B & $\mathrm{C}$ \\
\hline 1 & Species & Material examined (copy these cells and paste into text) \\
\hline 2 & Filistatinella domestica & \&\&\&Non-type material: \&\&\&\#\#Mexico.\#\# \$\$\$Chiapas:\$\$\$ \%\%\%Lagunas de Montebello,\%\%\% Posada de Bosque Bello, [E22.31919, S102.16783], P.R. Cra \\
\hline 3 & Filistatinella hermosa & 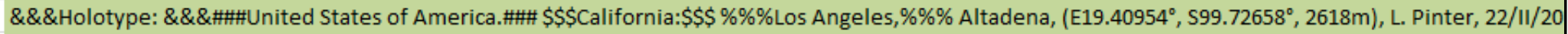 \\
\hline 4 & Filistatinella kahloae & 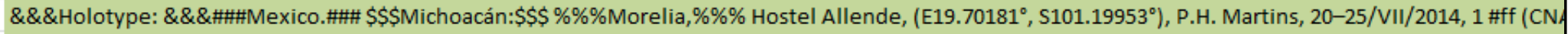 \\
\hline 5 & Filistatinella pistrix & 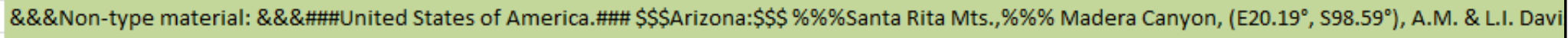 \\
\hline 6 & Filistatinella tohono & 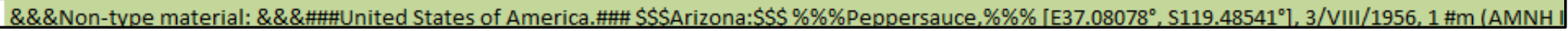 \\
\hline
\end{tabular}

The tagged output of Filistatinella hermosa reads like this:

\&\&\&olotype: \&\&\&\#\#United States of America.\#\#\# \$\$California:\$\$ \%\%Los Angeles,\%\% A1tadena,

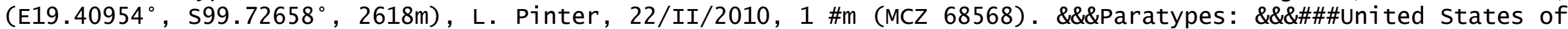
America.\#\#\# \$\$California:\$\$ \%\%Santa Cruz Island,\%\% (E19.40954\%, S99.72658 $\left.{ }^{\circ}, 2618 \mathrm{~m}\right)$, R.V. Chamber1in, 22/II/2010, 1 \#ff 1 imm. (AMNH IFM-1232); \%\%Santa Monica,\%\% (E19.58\%, S98.51\%), W. IVie, 22/IV/1963, subadult female, 4 \#ff (AMNH IFM-1147). \&\&\&Non-type material: \&\&\&\#\#United States of America.\#\#\#

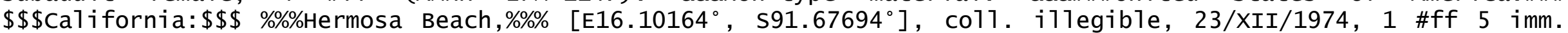
(AMNH IFM-1161); \%\%Santa Monica,\%\% (E20.5\%, S99.25\%), W. IVie, 22/IV/1963, 1 imm. (AMNH).

After applying formatting automatically using the tags, the final result is:

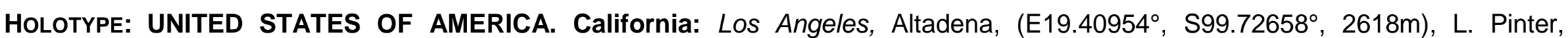
22/II/2010, 1 \#m (MCZ 68568). PARATYPES: UNITED STATES OF AMERICA. California: Santa Cruz Island, (E19.40954, S99.72658

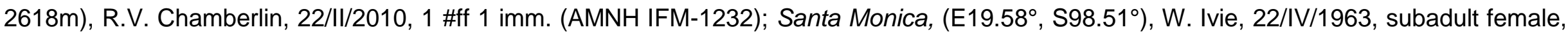

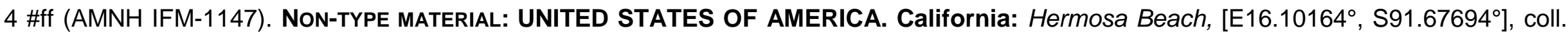
illegible, 23/XII/1974, 1 \#ff 5 imm. (AMNH IFM-1161); Santa Monica, (E20.5, S99.25), W. Ivie, 22/IV/1963, 1 imm. (AMNH). 


\section{Formatting the text using tags:}

To use the tags to apply formatting, follow these steps (in MS Word 2007-2010):

1- Open the Find and Replace menu and click on the More button;

2- Check the Use wildcards option;

3- On the Find what field, indicate the tag you want to replace (e.g. $\$ \$ \$ \$ \$ \$$ ). The asterisk indicates that any text between dollar signs will be formatted.

4- Select the Replace with field but do not introduce any text in it. Instead, click the Format button and select which format you want to apply for that particular tag (e.g. bold, italics, small caps, etc.).

5- Click Replace all. The desired formatting should be applied throughout the manuscript.

6- Now we need to remove the tags. Select the Replace with field and click No formatting, leaving the field empty. Then, select the Find what field and introduce only the tag (e.g. \$\$). Click Replace all to remove that particular tag.

7- Repeat the process for each different tag you had applied to your text (e.g. $\$ \$$, \%\%\%, \#\#, etc.).

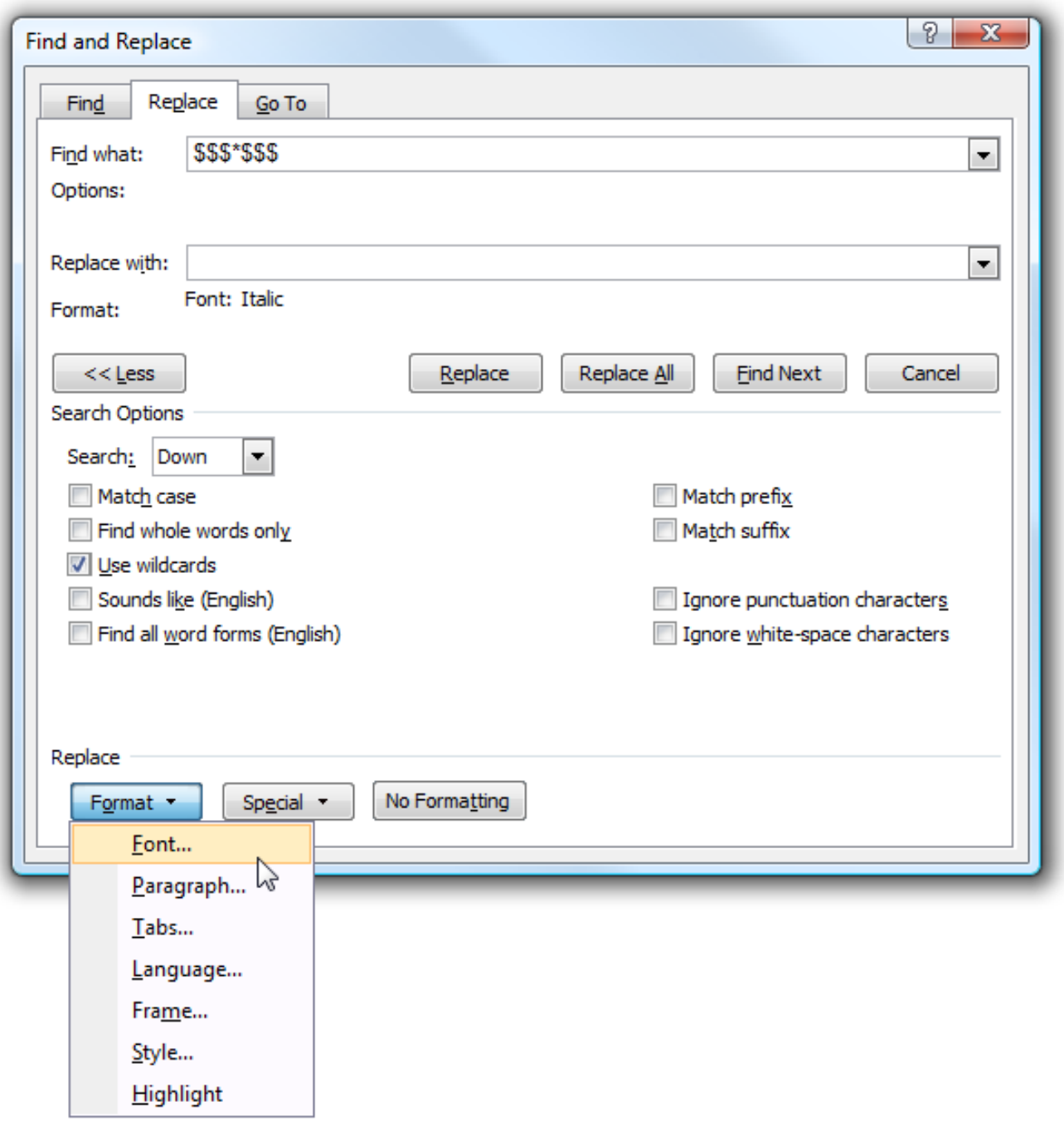

